\title{
Edible brown seaweeds: a review
}

\author{
K.K. Asanka Sanjeewa and You-Jin Jeon*
}

Laboratory of Marine Bioresource Technology, Department of Marine Life Science, School of Marine Biomedical Sciences, Jeju National University, Jeju 63243, Republic of Korea

${ }^{*}$ Corresponding author: You-Jin Jeon, Department of Marine Life Sciences, School of Marine Biomedical Sciences, Jeju National University, Jeju 63243, Republic of Korea. Tel: +82647543475; Fax: +82647563493; E-mail: youjinj@jejunu.ac.kr

DOI: $10.31665 / J F B .2018 .2139$

Received: March 08, 2018; Revised received \& accepted: June 11, 2018

Citation: Sanjeewa, K.K.A., and Jeon, Y.-J. (2018). Edible brown seaweeds: a review. J. Food Bioact. 2: 37-50.

\begin{abstract}
Seaweeds play a vital role as a source of food and ingredients in traditional Korean medicine. Koreans consume seaweed as fresh vegetables, salad, soups, or snacks. There are several edible brown seaweed species are abundant along the shores of the Korean peninsula, such as Ecklonia cava, Hizikia fusiforme, Laminaria japonica, Pelvetia siliquosa, Sargassum fulvellum, and Undaria pinnatifida. With the growing body of scientific evidence, it is clear that these brown seaweeds are not only good substitutes for land vegetables but also a good source of bioactive secondary metabolites. The secondary metabolites identified from edible Korean brown seaweeds (phlorotannins, sulfated polysaccharides, pigments, and sterols) have the potential to be developed as functional food ingredients. However, seaweeds consumption and their industrial level applications as functional materials are limited compared to the land vegetables. Insufficient awareness about health benefits of seaweeds might be the reason for this issue. Thus, in this review health promotion properties associated with edible Korean brown seaweeds are summarized. The present study might therefore increase consumption and industrial use of brown seaweeds.
\end{abstract}

Keywords: Seaweeds; Bioactive compounds; Functional foods.

\section{Introduction}

Seaweeds are important macroscopic marine organisms with great economic and ecological value. In East-Asia (Korea, China, and Japan) seaweeds serve as healthy food and medicinal ingredients (Jeong et al., 2015). The term "sea vegetable" is used to define seaweeds include approximately 50 different species of edible seaweeds in this region (Park et al., 2016). Besides the nutrient value, a growing body of scientific evidence indicates that the secondary metabolites present in seaweeds have great potential for developing active ingredients in functional products. Phlorotannins, sulfated polysaccharides, ergosterol, and some pigments isolated from seaweeds have been found to possess outstanding bioactive functionalities (antioxidant, anticoagulant, anticancer, anti-microbial, anti-diabetic, and anti-inflammatory activities) compared to the synthetic chemicals under in vivo and in vitro conditions (Jeong et al., 2015; Son et al., 2018).

Korea is one of the major seaweed producers and consumers in the global seaweed market and makes great contributions to the Korean economy. Seaweeds have more than thousands of year's history in Korea as food and medicinal ingredients, and increases the food security and healthy lifestyle of Koreans (Choi et al., 2012). During winter (December to February), Koreans enjoy seaweed as a vegetable substitute in the winter season (Park et al., 2016). Figure 1 graphically illustrates common seaweed applications including traditional meals, cosmeceutical and functional food ingredients found in Korea. On the basis of their color and appearance, seaweeds are categorized into three groups as brown, green, and red. All three seaweed types have been found to possess interesting bioactive properties and are useful for a range of industrial applications (Wijesinghe and Jeon, 2012a). However, in the present study, we have focused about the potential health promotion properties of edible brown seaweeds consumed in Korea including Ecklonia cava, Hizikia fusiformis, Sargassum fulvellum, Laminaria japonica, Undaria pinnatifida, and Pelvetia siliquosa. 


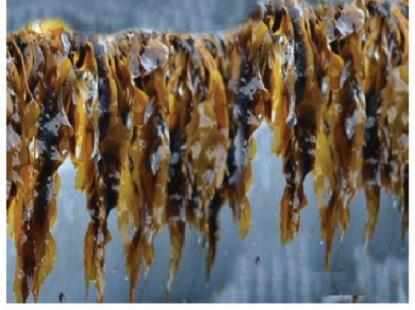

Large scale commercial cultivation for industrial and traditional applications

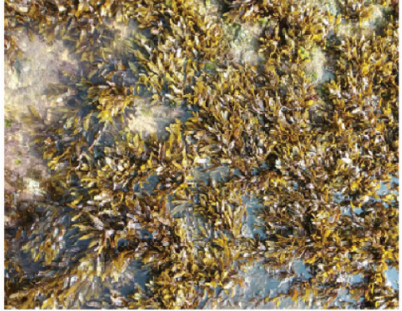

Collect from the wild for

industrial and traditional applications

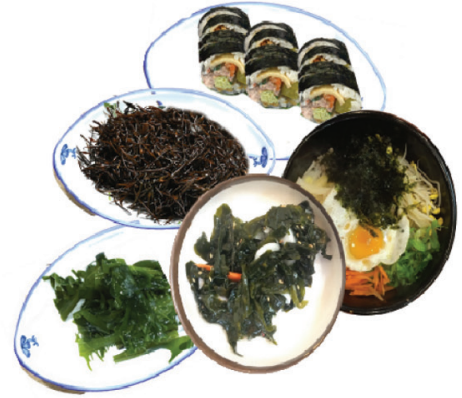

Food applications
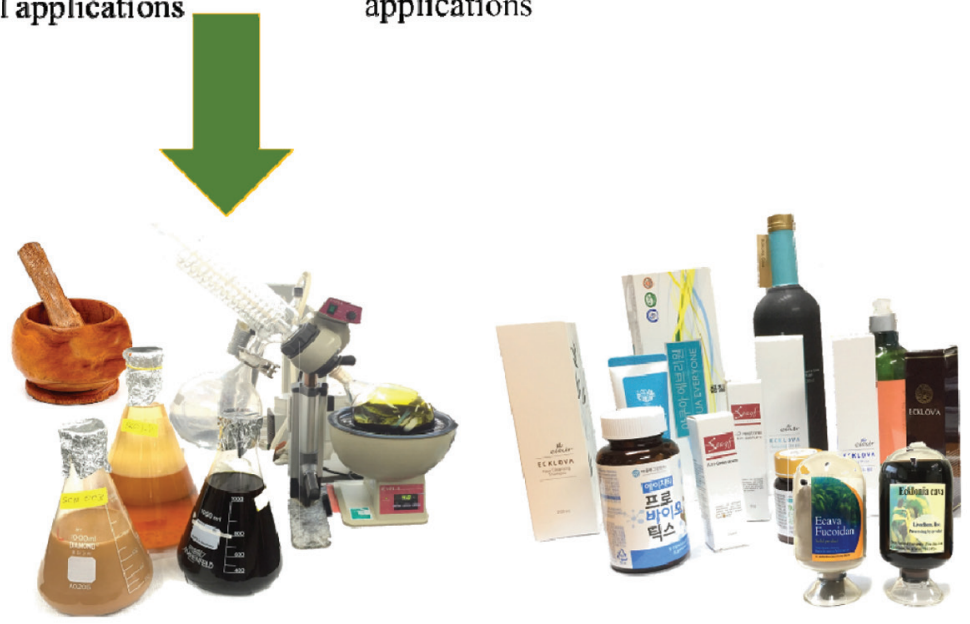

Medicinal applications
Commercial applications

Figure 1. Common applications of seaweeds.

\section{Brown seaweeds}

\subsection{Ecklonia cava (Kamthe)}

Ecklonia cava is a brown alga, abundantly found in the subtidal regions of Jeju Island, Korea. E. cava, is popular as a food ingredient, fertilizer, as an ingredient in folk medicine, and animal feed stock in Korea and Japan (Le et al., 2009). Specifically, E. cava, is commercially cultivated to supply a summer feed for the abalone industry in Korea (Hwang et al., 2012a). E. cava has been identified as a potential source of a wide spectrum of secondary metabolites such as phlorotannins, sulfated polysaccharides, and carotenoids. The compounds isolated from this seaweed have shown interesting biological activities in vital industrial applications including functional foods, pharmaceuticals, cosmeceuticals, and nutraceuticals (Wijesinghe and Jeon., 2012a). Previously, a number of studies have reported that the secondary metabolites isolated from $E$. cava render bioactive properties such as antioxidant, anti-diabetes, anti-coagulative, anticancer, antimicrobial, anti-inflammatory, and anti-human immunodeficiency virus (HIV).

\subsection{Hizikia fusiforme (Tot)}

Hizikia fusiformis is a huge annual brown seaweed that grows in
Korea, China, and Japan. H. fusiformis is abundant in southern coast, west coast, and Jeju Island in Korea. In the traditional Chinese medicine $H$. fusiformis have been used as an active ingredient for thousands of years (Park et al., 2017). H. fusiformis is a popular edible seaweed in East-Asian countries. Besides Korea, $H$. fusiformis is also popular in Japan and China as an edible seaweed (Choi et al., 2009). Tot grows from the foot of the eulittoral to the upper part of the sublittoral zone, around the Korean peninsula. Tot is preserved as a salad, fried with vegetables, and often used as an ingredient in bi-bim-bap. Bi-bim-bap is a mixture of seasoned vegetables, rice, and a paste prepared from chili paper. Recently, the market demand for food and other functional products prepared from $H$. fusiformis has increased due to the excellent nutritional value as well as health promotion properties associated with $H$. fusiformis (Hu et al., 2013). However, Nakamura et al. (2008) have reported that cooked tot also contains a considerable amount inorganic arsenic. Thus, the authors have proposed that the regular consumption of cocked tot might increase cancer risk due to the presence of inorganic arsenic in tot (Nakamura et al., 2008).

\subsection{Laminaria japonica (Da-si-ma)}

Laminaria japonica is an important seaweed cultured in Korea and commercially cultivated in the temperate seaside areas of northwest Pacific region. L. japonica is a popular sea vegetable in many 


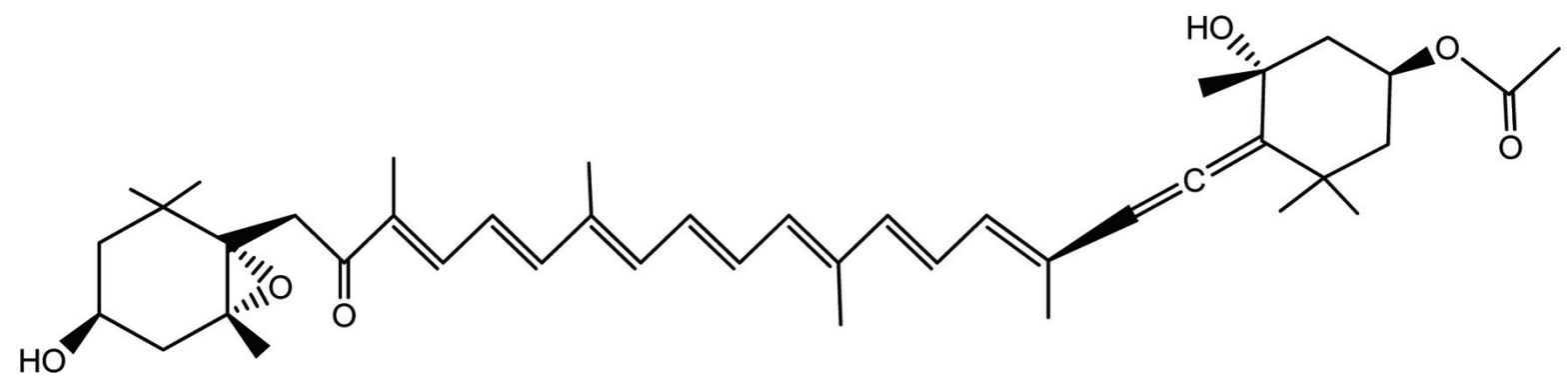

Figure 2. Chemical structure of fucoxanthin.

Asian and Pacific countries including Korea. L. japonica is used as an ingredient in traditional Korean medicine. A soup prepared from L. japonica is used to increase maternal health recovery of women after giving birth (Post-natal). (Choi et al., 2012; Islam et al., 2013). In addition, L. japonica use as a medicinal ingredient in traditional Japanese and Chinese medicine (anti-thrombosis, gall disease, hard lump, edema, anti-thyroid tumor, tuberculosis and beriberi drugs) to treat various disease conditions (Mei et al., 2017; Wang et al., 2018; Zeng et al., 2017). Sliced L. japonica (5-6 cm long strips) is boiled with hot water to prepare soup and dried $L$. japonica is used as a cookie with green tea, or pickled in vinegar. In addition, L. japonica is also mixed with various traditional Korean food products like bread, muffins, and cake to enhance flavor and quality of the food products (Choi et al., 2012).

\subsection{Pelvetia siliquosa (Tumbugi)}

Pelvetia siliquosa is another popular edible brown seaweed in Korea. $P$. siliquosa belongs to the family Fucaceae and abundantly grows in the rocky areas of the southern seashores of Korea. $P$. siliquosa is consider an important source of seafood and used as a source of alginic acid. Traditionally, P. siliquosa has been consumed as seasoned sea greens for religious services, as well as in soup or fresh seafood salad (Hwang et al., 2012b). A number of studies have reported that the metabolites present in tumbugi have bioactive properties such as anti-diabatic and antioxidant effects (Lee et al., 2003; Lee et al., 2004).

\subsection{Sargassum fulvellum (Mo-Ja-ban)}

Sargassum fulvellum is a popular seafood in the Korean food market. S. fulvellum is an abundant seaweed from southern coast to the eastern coast of Korea. People living in Jeju Island of Korea use this seaweed to prepare salad, soup (Mom-Guk) or use it to prepare side dishes (Choi et al., 2007a; Hwang et al., 2007). In addition to its food value, in the traditional medicine $S$. fulvellum is used as a medicine to treat diseases such as a dropsy, lump, swollen, painful scrotum, and to treat urination problems (Gwon et al., 2013; Kang et al., 2008). As claimed by the previous studies, S. fulvellum is a potential candidate for developing functional material due to the interesting bioactive properties such as antioxidant, anticancer, and anticoagulant (De Zoysa et al., 2008; Kang et al., 2008).

\subsection{Undaria pinnatifida (Mi-Yeok)}

Korea is one of the largest commercial cultivator of $U$. pinnatifida (Choi et al., 2007b). This seaweed has a long history in Korea and
Japan as an edible product. The coastal areas located in south part of Korea is popular for growth and cultivation of $U$. pinnatifida. Fucoxanthin is one of the major bioactive compounds present in $\mathrm{Mi}$ Yeok. Fucoxanthin isolated from Mi-Yeok owing a number of bioactive properties such as antioxidative, anti-cancerous, anti-obesity, angiotensin-converting-enzyme inhibitory, and anti-inflammatory (Prabhasankar et al., 2009; Suetsuna and Nakano, 2000). U. pinnatifida is generally served in soup, salad, and side dishes (Kim, 2010). In addition, U. pinnatifida is a popular seafood among Korean mothers. Soup prepared from Mi-Yeok is served to lactating mothers to help to increasing postpartum convalescence (Cho et al., 2007).

\section{Bioactive compounds reported from edible brown seaweeds}

\subsection{Carotenoids}

Carotenoids are red, orange, and yellow color pigments present in plant leaves, fruits, and flowers. Plants, bacteria, fungi, and algae are the producers of carotenoids. However, carotenoids are also responsible for color spot present in birds, insects, fish, and crustaceans, because many animals incorporate carotenoids to their bodies from their diet (Stahl and Sies, 2003). Carotenoids in photosynthetic organisms help in photosynthesis, photo-protection, phototropism, and photo-reception, and act as a repellent for their natural enemies (Dembitsky and Maoka, 2007; Matsuno, 2001). The central chain of carotenoids is build up with cyclic end-groups substituted with oxygen-containing functional groups. According to their composition, carotenoids are divided into two groups as carotenes and oxocarotenoids or xanthophylls (Stahl and Sies, 2003). Fucoxanthin (Fig. 2) is a well-known carotenoid pigment present in brown seaweeds. Fucoxanthin accounts for around 10\% of the total natural production of seaweed carotenoids (Matsuno, 2001). With interesting bioactive properties associated with fucoxanthin, which is a popular ingredient in industries like functional food, cosmeceutical, and nutraceuticals (Peng et al., 2011; Miyashita and Hosakawa, 2018).

\subsection{Polyphenols}

Polyphenols are water-soluble chemical compounds present in cell vacuole (Harborne, 1998; Manach et al., 2005). Polyphenols are capable of reacting or pairing with one-electron oxidants formed during biological processes. Due to their high electron donating ability, polyphenols are considered as one of the best class of bioactive compounds present in nature (Handique and Baruah, 2002). Polyphenols reported from land plants are polymers of flavonoids and gallic acid and similarly occur in brown seaweeds (phlorotannins) as 
<smiles>Oc1cc(O)cc(O)c1</smiles>

Phloroglucinol<smiles>OC1=CC2Oc3c(O)cc(O)c(Oc4cc(O)cc(O)c4)c3OC2C(O)=C1</smiles>

Eckol<smiles>Oc1cc(O)c2oc3cc(O)cc(O)c3c3oc4c(O)cc(O)cc4c3oc2c1</smiles>

Eckstolonol<smiles>Oc1cc(O)cc(Oc2c(O)cc3c(c2O)Oc2cc(Oc4c(O)cc(O)cc4O)c(O)c(O)c2O3)c1</smiles>

Diphlorethohydroxycarmalol<smiles>OC1=CC2OC(Oc3c(O)c(Oc4cc(O)c(Oc5c(O)cc(O)c6c5OC5Oc7c(O)cc(O)c(Oc8cc(O)cc(O)c8)c7OC(O)=CC5O6)cc4O)cc(O)c32)C(O)=C1</smiles>

Dieckol<smiles>OC1=CC(O)C(Oc2cc(O)cc(O)c2Oc2cc(O)cc(O)c2-c2c(O)cc(O)cc2O)C(O)=C1</smiles>

Fucodiphlorethol-G<smiles></smiles>

Dioxinodehydroeckol<smiles>OC1=Cc2oc3c(Oc4cc(O)cc(O)c4)c(O)cc(O)c3c2C2(OCc3cccc(O)c3)c3c(O)cc(O)c(Oc4cc(O)cc(O)c4)c3OC12</smiles>

Phlorofucofuroeckol A

Figure 3. Bioactive phlorotannins isolated from brown seaweeds.

chains of 1,3,5-trihydroxybenzene formed in the acetate-malonate pathway (Li et al., 2011). Phlorotannins produced by brown seaweeds act as herbivore deterrent, digestive inhibitor, UV screen, and antibacterial agents that protect seaweeds from their natural enemies (Targett and Arnold, 1998). In addition, some studies have confirmed that, phlorotannins render a range of bioactive properties such as antioxidant, anticancer, ant-inflammation, anti-allergic, antibacterial, and matrix metalloproteinase inhibition (Wijesinghe and Jeon, 2012b). Due to these diverse bioactive properties, phlorotannins have been identified as an important seaweed metabolite to use as a functional ingredient in food products, pharmaceuticals, and cosmeceuticals (Li et al., 2011). Figure 3 illustrates the structures of some phlorotannins isolated from brown seaweeds.

\subsection{Polysaccharides}

\subsubsection{Alginic acid}

Alginic acids are high-molecular-weight polysaccharides reported from the brown seaweed cell wall. Alginic acids are alkali-solu- ble polysaccharide where the other cell wall constitutes such as fucoidan and laminarin are water-soluble. In water, alginic acid forms a mechanically stable porous hydrogel. Moreover, seaweeds contain approximately $10-40 \%$ of alginic acid from on a dry weight basic. Growing depth and seaweed growth season determine the amount of alginic acid in the seaweed biomass (Marriott et al., 2016; Rioux et al., 2007). Alginic acid comprises two kinds of hexuronic acids including $\alpha$-1,4-linked L-guluronic acid and $\beta$-1,4-linked D-mannuronic acid residues arranged in homopolymeric blocks separated by regions of alternating sequences of the two monomers (Fig. 4) (Marriott et al., 2016). In the food industry, alginates are used as thickening agents or metal ion chelators (Gupta and Abu-Ghannam, 2011). In addition, alginates have also been used as an immune-stimulant in aquaculture to increase disease resistance and non-specific immune responses in aquatic species such as abalone, shrimp, and grouper (Lee et al., 2017).

\subsubsection{Fucoidans}

Fucoidans are a class of sulfated polysaccharide extracts from 


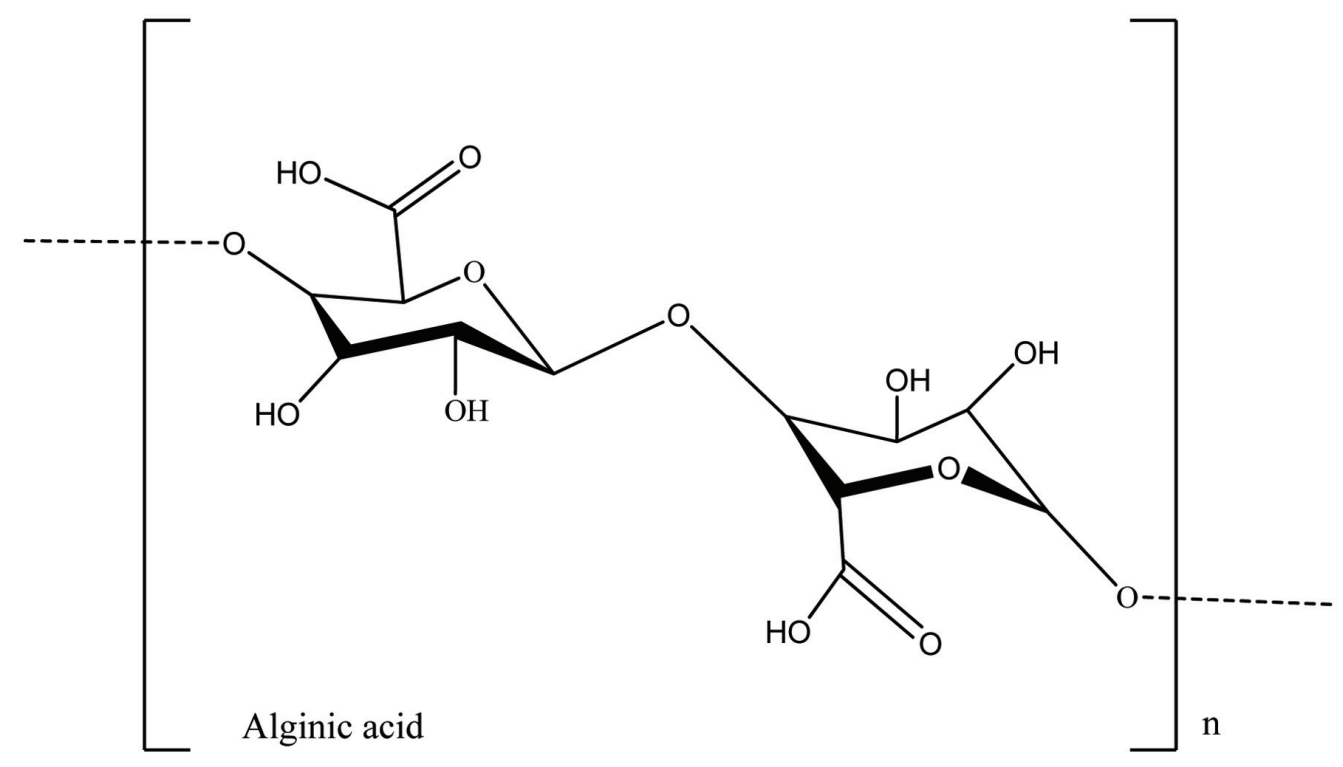

Figure 4. The chemical structure of alginic acids present in brown seaweeds.

brown seaweeds. During the past few decades, fucoidan has gained considerable attention in the biomedical research studies due to its diverse bioactive properties like anti-coagulant, antioxidant, anticancer, anti-inflammatory, and immune-modulatory effects (Sanjeewa et al., 2017). Classically, backbone of fucoidan is made of $\alpha(1 \rightarrow 3)$-L-fucopyranose residues or alternating $\alpha(1 \rightarrow 3)$ and $\alpha(1$ $\rightarrow 4$ )-linked L-fucopyranosyls or both forms. Moreover, fucoidans contain monosaccharides such as fucose (mainly), mannose, galactose, glucose, arabinose, uronic acids, and xylose (Sanjeewa et al., 2017). Due to the significant differences in fucoidan structure
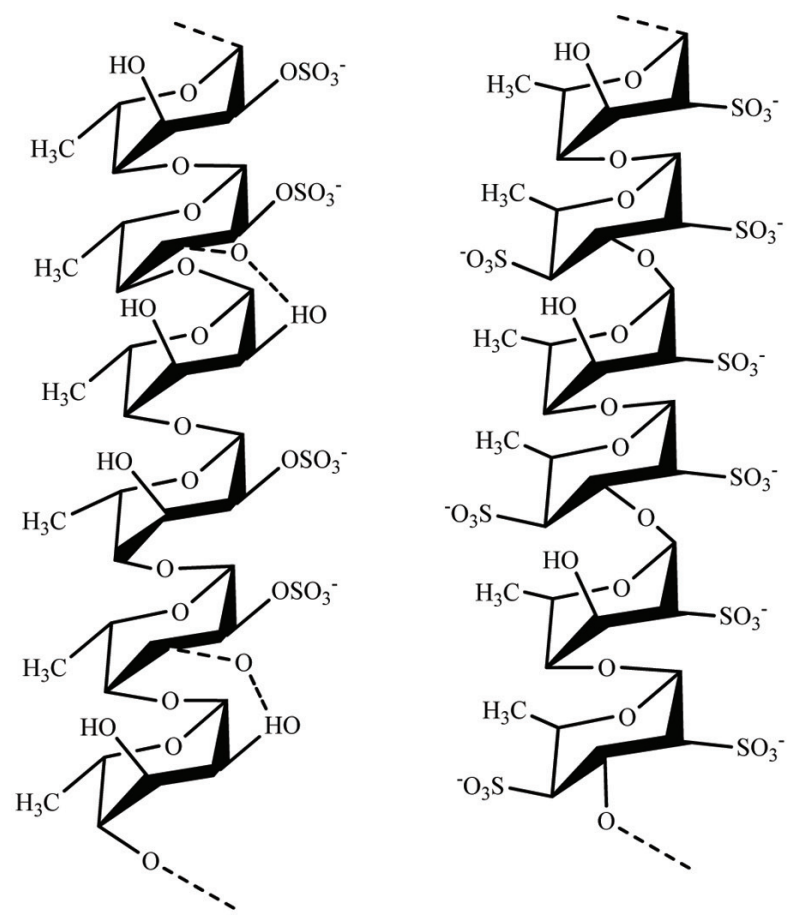

(fucose linkage, sulfate position, and sugar composition), they are very diverse (Fig. 5) and their structures depend on the species, season, location, and growth stage of the seaweed (Fletcher et al., 2017).

\subsubsection{Laminaran}

Laminaran is a major storage polysaccharide present in brown seaweeds (Fig. 6). Laminaran represents $35 \%$ of seaweed on a dry
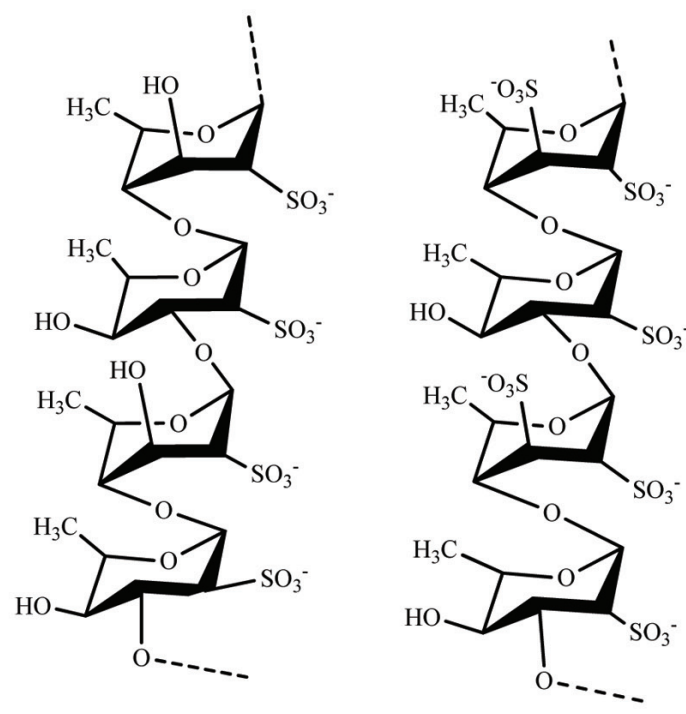

Figure 5. Structural motifs of fucoidans present in brown seaweeds. 


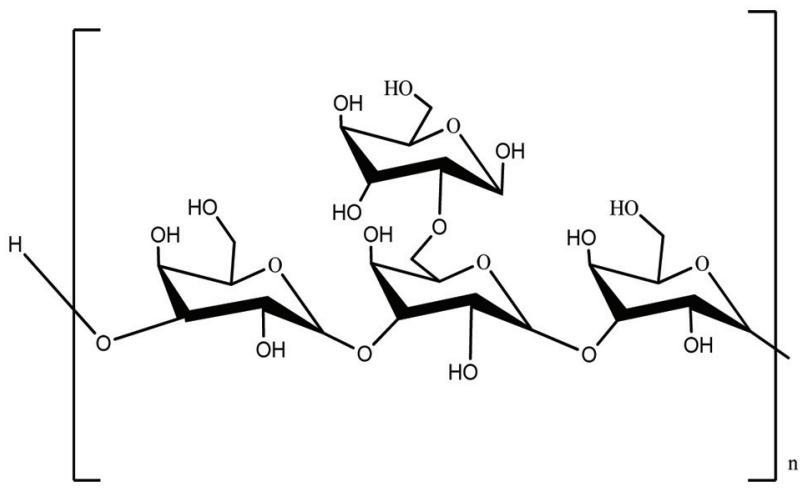

Figure 6. Chemical structure of laminarin presents in brown seaweeds.

weight basis. The percentage of laminaran depends on seaweed species, harvesting time, and extraction method (Yin et al., 2014). Laminaran consists of glucose monomers joined together mainly by $(1,3)-\beta$-D-glucan backbone with $\beta(1,6)$ glycosidic bonds. Laminarans may be separated into two groups as $\mathrm{G}$ and $\mathrm{M}$ chains, where $\mathrm{M}$ chains end with a mannitol as the terminal reducing end and glucose is attached to the end of the G chains. It has been reported that laminaran possesses interesting bioactive properties such as antioxidant, antitumor, anti-inflammatory, and anticoagulant activities (Sanjeewa et al., 2017).

\subsection{Sterols}

Sterols are major components in the plasma membranes of all eukaryotes $(20-30 \%)$ but are absent in prokaryotes. Cholesterol is the major sterol in animals, fungi, and yeast capable to produce ergosterol. Other than that phytosterols and fucosterol are major sterols present in higher plants and seaweeds, respectively (Mouritsen et al., 2017; Sanjeewa et al., 2016). Sterols in seaweeds serve as a substantial source of bioactive ingredients. A number of studies have reported that sterols such as ergosterol and fucosterol (Fig. 7) have the potential to be incorporated as an active ingredient in functional food products (Kim and Ta, 2011).

\section{Bioactivities of brown seaweed polysaccharides}

\subsection{Antioxidant ability}

According to the previous reports, edible seaweeds grow along the shores of the Korean peninsula, H. fusiformis, L. japonica, and E. cava bio-synthesize secondary metabolites with strong antioxidant properties. Some antioxidant properties of edible brown seaweeds growing along the shores of the Korean peninsula are discussed here.

Siriwardhana et al. (2003) studied the reactive oxygen species (ROS) scavenging and lipid peroxidation inhibition activities of water and organic extracts separated from $H$. fusiformis respectively. According to the results, water extract of $H$. fusiformis had the highest DPPH radical scavenging activity among the other tested extracts (methanol and ethanol). Additionally, the authors reported, that the radical scavenging activities of water extract were stronger than those of the commercial antioxidant (BHA, BHT, and $\alpha$-tocopherol) under tested conditions (Siriwardhana et al., 2003). Tong et al. (2012) evaluated the antioxidant properties of the extracts separated from three seaweeds including $H$. fusiforme, Capsosiphon fulvescens, and U. pinnatifida collected from Wando, Korea. Among the tested seaweed extracts, $H$. fusiforme had a better DPPH radical scavenging activity $(90.12 \%$, at a $0.32 \mathrm{mg} / \mathrm{mL}$ concentration), followed by $U$. pinnatifida. Additionally, the reducing power of extract of $U$. pinnatifida and $H$. fusiforme had better effects compared to Capsosiphon fulvescens (Tong et al., 2014). Lee and Kang (2015) evaluated DPPH radical scavenging effect of $70 \%$ ethanolic extract separated from H. fusiformis. According to the authors, $H$. fusiformis extract significantly scavenged DPPH radicals with $\mathrm{IC}_{50}$ of $9.64 \pm 0.78 \mu \mathrm{g} / \mathrm{mL}$ (Lee and Kang, 2015). Wu et al. (2016) reported a novel lectin $(65 \mathrm{kDa})$ isolated from $\mathrm{H}$. fusiformis which has the potential to incorporate it as an active ingredient in functional food products. At $1.6 \mathrm{mg} / \mathrm{mL}$ concentration, the isolated lectin inhibited DPPH and hydroxyl radicals by 77.23 and $33.65 \%$, respectively (Wu et al., 2016). However, compared to the DPPH inhibitory effect of $70 \%$ ethanolic extract (reported by Lee and Kang 2015), the inhibitory effect of lectin was very low. Kim (2010) evaluated the total phenolic contents and antioxidant activities of U. pinnatifida and Capsosiphon fulvescens under different drying conditions. The authors reported that radical scavenging

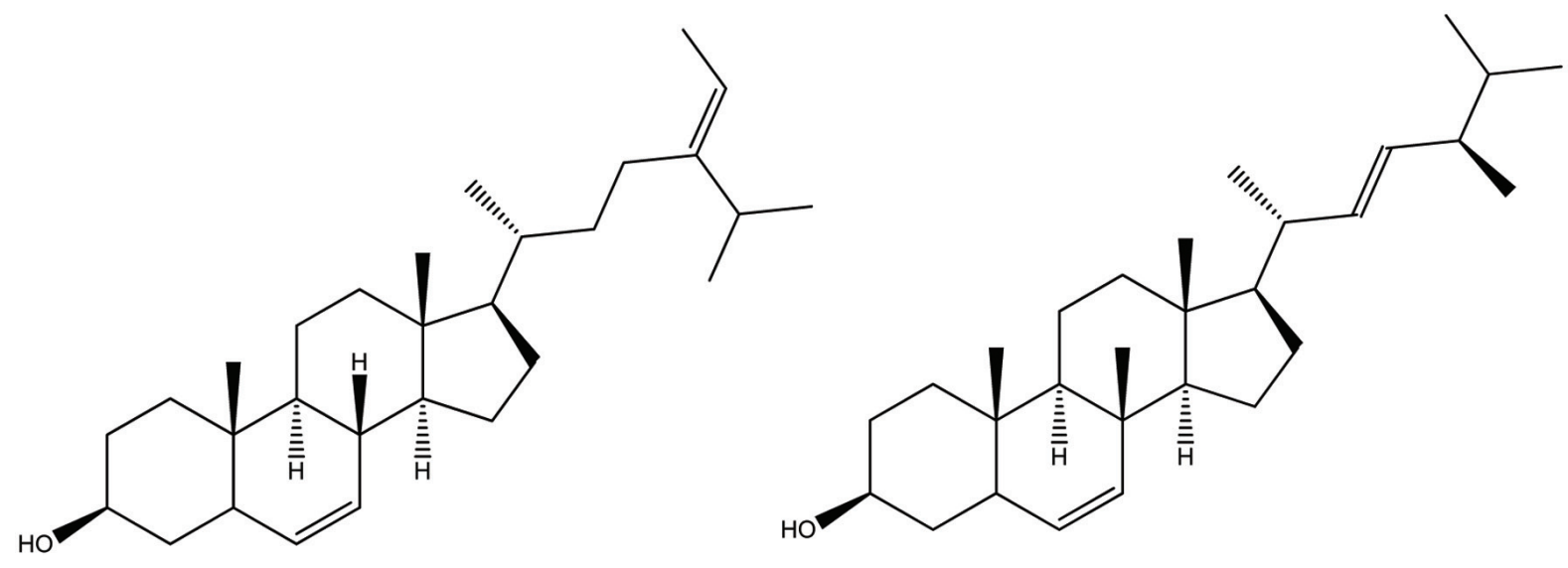

Fucosterol

Ergosterol

Figure 7. Chemical structure of two major sterol present in seaweeds. 
Table 1. Antioxidant properties reported from edible Korean brown seaweeds

\begin{tabular}{|c|c|c|c|}
\hline Seaweed & Active compound/fraction & Effect & Reference \\
\hline \multirow[t]{6}{*}{ H. fusiformis } & Water extract & DPPH radical scavenging & Siriwardhana et al., 2003 \\
\hline & Crude phenolic & DPPH radical scavenging & Tong et al., 2014 \\
\hline & $70 \%$ Ethanolic extract & DPPH radical scavenging & Lee and Kang, 2015 \\
\hline & $70 \%$ Ethanolic extract & $\begin{array}{l}\text { Protective effect against radiation- } \\
\text { induced damage in splenocytes }\end{array}$ & Kim et al., 2015 \\
\hline & Polysaccharides & $\begin{array}{l}\text { Protection against } \mathrm{CCL}_{4} \text { induced liver } \\
\text { damage in } \mathrm{BALB} / \mathrm{c} \text { mouse }\end{array}$ & Wu et al., 2013 \\
\hline & Lectin (65 kDa) & DPPH radical and hydroxyl radical scavenging & Wu et al., 2016 \\
\hline \multirow[t]{4}{*}{ L. japonica } & Low molecular weight Polysaccharides & Superoxide radical scavenging properties & Zha et al., 2016 \\
\hline & Crude polysaccharide & $\begin{array}{l}\text { oxygen radical absorbance capacity } \\
\text { and ABTS radical scavenging }\end{array}$ & Cui et al., 2016 \\
\hline & Crude polysaccharides & $\begin{array}{l}\text { oxygen radical absorbance capacity } \\
\text { and ABTS radical scavenging }\end{array}$ & Yao et al., 2017 \\
\hline & Fucoidan & DPPH radical and hydroxyl radical scavenging & Zhao et al., 2018 \\
\hline \multirow[t]{2}{*}{ E. cava } & Phlorotannins & DPPH and hydroxyl radical scavenging & Cha et al., 2012 \\
\hline & Fucoidan & $\begin{array}{l}\text { Protective effect against hydrogen peroxide-induced } \\
\text { cytotoxicity in PC-12 and MC-IXC neuronal cells }\end{array}$ & Park et al., 2018 \\
\hline S. fulvellum & Sulphated polysaccharides & DPPH radical scavenging & Choi et al., 2007a \\
\hline \multirow[t]{4}{*}{ U. pinnatifida } & Crude phenolic extracts & DPPH radical scavenging & Kim, 2010 \\
\hline & Ethanolic extract & $\begin{array}{l}\text { Hypoxia/reoxygenation-induced oxidative } \\
\text { stress inhibition in neuronal cells }\end{array}$ & Mohibbullah et al., 2015 \\
\hline & Crude phenolic & DPPH radical scavenging activity & Tong et al., 2014 \\
\hline & Fucoidan & $\begin{array}{l}\text { DPPH, hydroxyl radical scavenging, } \\
\text { and iron chelating ability }\end{array}$ & Phull et al., 2017 \\
\hline
\end{tabular}

activity and phlorotannins contents were comparatively high in the extracts separated from vacuum dry method compared to the hot air dry method. Thus, the antioxidant properties of seaweeds extracts depended on the processing method employed (Kim, 2010). Zha et al. (2016) evaluated the antioxidant properties of different molecular weight polysaccharides separated from L. japonica using superoxide radical scavenging properties of polysaccharides. Their results confirmed, that the low-molecular-weight polysaccharide fraction had a better superoxide radical scavenging effect than the high-molecular-weight fraction (Zha et al., 2016). Cui et al. (2016) reported that a polysaccharide [mole ratio of galactose, mannose and fucose (26.1:1.3:1) and 1,3- and 1-linked galactose] separated from L. japonica had remarkably high oxygen radical absorbance capacity $\left(1247.22 \mu \mathrm{mol}\right.$ trolox equants $\left.\mathrm{g}^{-1}\right)$ and ABTS $(-70 \%$ at $4 \mathrm{mg} / \mathrm{mL})$ scavenging activities (Cui et al., 2016). In another similar study, antioxidant effect of polysaccharide separated from L. japonica was documented by Yao et al. (2017). In this study, the authors compared the antioxidant capacity of polysaccharide extracted from different extraction methods such as water extraction and acidic extraction (citric acid, sulfuric acid, hydrochloric acid, and phosphoric acid). According to the results, polysaccharides from citric acid aided extraction method had good ABTS radical scavenging activity $\left(\mathrm{IC}_{50}=1.06 \mathrm{mg} / \mathrm{mL}\right)$ and oxygen radical absorbance capacity $\left(341.87 \mu \mathrm{mol}\right.$ trolox equants $\left.\mathrm{g}^{-1}\right)$ under the test conditions (Yao et al., 2017). In addition, antioxidant properties of pigment-free fucoidan separated from $L$. japonica was also reported (Zhao et al., 2018). The results revealed L. ja- ponica fucoidan had the potential for developing as antioxidant materials. Under the test conditions, the isolated fucoidans had a better DPPH radical scavenging $\left(\mathrm{IC}_{50}=4.64 \mathrm{mg} / \mathrm{mL}\right)$ and hydroxyl radical scavenging activity. A sulfated polysaccharide fraction $(529 \mathrm{kDa})$ from $S$. fulvellum possessed a strong hydrogen peroxide scavenging activity compared to the commercial antioxidant such as BHA and $\alpha$-tocopherol. Additionally, the separated polysaccharides inhibited the superoxide radicals, nitric oxide radicals, and DPPH in a dose-dependent manner (Choi et al., 2007a).

Other than the radical scavenging effects, some studies reported that extracts and pure compounds separated from edible brown seaweed render strong antioxidant properties under in vitro and in vivo conditions. Here we briefly introduce a few curious studies reporting in vitro and in vivo antioxidant properties of edible Korean brown seaweeds. Cha et al. (2012) studied the protective effect of E. cava phlorotannins on UV-induced ROS production in in vivo zebrafish model. The results confirmed that, pretreatment of eckol, eckstolonol, phloroglucinol, and triphlorethol-A $(50 \mu \mathrm{M})$ protect zebrafish against UV-induced ROS generation, NO production, and cell death. In addition, the authors also studied the Inhibitory effect of phlorotannins on UV-B-induced hyperpigmentation in zebrafish embryos. Further they have reported that phlorotannins inhibited the UV-B induced melanin production in zebrafish embryos (Cha et al., 2012). Later, Wu et al. (2013) proclaimed that the water-soluble polysaccharides isolated from $H$. fusiformis had a protective effect on $\mathrm{CCL}_{4}$ induced liver damage in $\mathrm{BALB} / \mathrm{c}$ mouse. In relation to the results, administration of separated polysaccharide at a rate of 200 
Table 2. Anticancer properties reported from edible Korean brown seaweeds

\begin{tabular}{|c|c|c|c|}
\hline Seaweed & Active compound/fraction & Cell line and effect & Reference \\
\hline \multirow[t]{5}{*}{ H. fusiformis } & Ethanolic extract & $\begin{array}{l}\text { Induce apoptosis via upregulating Tumor necrosis } \\
\text { factor-related apoptosis-inducing ligand. } \\
\text { *AGS human gastric adenocarcinoma cells }\end{array}$ & Kim et al., 2009 \\
\hline & Ethanolic extract & $\begin{array}{l}\text { Inhibit matrix metalloproteinase and tumour } \\
\text { invasiveness and metastasis-related genes in } \\
\text { Hep3B human hepatocarcinoma cells }\end{array}$ & Kim and Choi, 2010 \\
\hline & Ethanolic extract & pre-neoplastic lesions progression in the colon & Son et al., 2018 \\
\hline & Ethanolic extract & Apoptosis cell death in human leukaemia U937 cells & Kang et al., 2011 \\
\hline & $\begin{array}{l}\text { 5-Hydroxy-3,6,7,8,3', } 4^{\prime}- \\
\text { hexamethoxyflavone }\end{array}$ & $\begin{array}{l}\text { Induction of expression death receptor- } \\
\text { associated apoptosis mediators } \\
\text { *AGS and DR4 cancer cells }\end{array}$ & Kim et al., 2012 \\
\hline \multirow[t]{4}{*}{ L. japonica } & Crude polysaccharides & Apoptotic cell death. Cervical carcinoma cells (HeLa and U14) & Zhai et al., 2014) \\
\hline & Crude polysaccharides & $\begin{array}{l}\text { Inhibitory effect on tumor growth (nasopharyngeal } \\
\text { cancer cell transplanted BALB/C nude mouse) }\end{array}$ & Zeng et al., 201 \\
\hline & Water soluble polysaccharide & $\begin{array}{l}\text { Induced the expression levels of interleukin-2 } \\
\text { (IL-2), TNF- } \alpha \text { and inhibited the expression of } \\
\text { vascular endothelial growth factor }\end{array}$ & Zhu et al., 2016 \\
\hline & Fucoxanthin & $\begin{array}{l}\text { Up-regulated expression of p53, p21 waf1/cip1, PUMA, and } \\
\text { FAS and the down-regulated expression of Bcl-2 in lung } \\
\text { cancer cells including A549, H460, SPC-A1, and H1299 }\end{array}$ & Mei et al., 2017 \\
\hline E. cava & Fucoidans & $\begin{array}{l}\text { Inhibited the colony formation of skin melanoma cell } \\
\text { (SK-MEL-28) and the colon cancer cells (DLD-1) }\end{array}$ & Ermakova et al., 2011 \\
\hline U. pinnatifida & Fucoidans & $\begin{array}{l}\text { Induce apoptosis in cancer cells including } \\
\text { HeLa, PC-3, A549, and HepG2. }\end{array}$ & Synytsya et al., 2010 \\
\hline
\end{tabular}

$\mathrm{mg} / \mathrm{kg} /$ day significantly reduced the $\mathrm{CCl}_{4}$ induced liver damage compared to the control group (Wu et al., 2013). Mohibbullah et al. (2015) compared the neuroprotective effect of 23 ethanolic extracts separated from seaweed against hypoxia/reoxygenation-induced oxidative stress in cultured hippocampal neurons. According to the authors, Gracilariopsis chorda (red alga) had the highest neuroprotection at $15 \mu \mathrm{g} / \mathrm{mL}$, followed by U. pinnatifida. (Mohibbullah et al., 2015). Kim et al. (2015) also evaluated the protective effect of $H$. fusiforme extract on radiation-induced damage in splenocytes (C57BL/6 mouse). In this study the authors demonstrated pre-incubation of splenocytes with $H$. fusiforme $(3.1-25 \mu \mathrm{g} / \mathrm{mL})$ extract prior to gamma-ray irradiation ( $1.5 \mathrm{~Gy})$ which had the potential to increase cell viability and proliferation by reducing elevated ROS levels in gamma irradiated splenocytes compared to the control group (Kim et al., 2015). In addition, fucoidan separated from $E$. cava was also found to possess protective effect against hydrogen peroxide-induced cytotoxicity in PC-12 and MC-IXC neuronal cells (Park et al., 2018). The isolated fucoidan restored mitochondrial damage by increasing the mitochondrial membrane potential $(\Delta \psi \mathrm{m})$ and ATP levels as well as regulating mitochondrial-mediated proteins (p-AMPK and BAX). The aforementioned antioxidant properties are summarized in Table 1.

\subsection{Anticancer activity}

Induction of apoptosis in cancer cells is a major strategy for eliminating cancer cells. Tumor necrosis factor-related apoptosisinducing (TNFAI) ligand is a transmembrane protein which capable of binding to its membrane-bound death receptors. Coupling of TNFAI and its receptor transmit an apoptotic signal via their intracellular death domains. Which can induce apoptosis in cancer cells (Kim et al., 2009). Kim et al. (2009) evaluated the anticancer effects of ethanolic extract separated from $H$. fusiforme on AGS human gastric adenocarcinoma cells. The results revealed that $H$. fusiforme extract $(0-25 \mu \mathrm{g} / \mathrm{mL})$ had the potential to induce apoptosis in cancer cells via up-regulating tumor necrosis factor- $\alpha$ (TNF- $\alpha$ ) expression in cancer cells (Kim et al., 2009). Later, Kim and Choi (2010) reported ethyl alcohol fraction separated from $H$. fusiforme has a potential to inhibit matrix metalloproteinase (MMP) activity and regulates tight junction related protein expression in Hep3B human hepatocarcinoma cells. In this study, the authors demonstrated the regulation of MMP activity related genes (MMP-1, MMP-2, TIMP-1, and TIMP-2) and tumor invasiveness and metastasis-related genes (claudins, E-cadherin, IGF-1R, and TSP-1) are responsible for induce apoptosis in cancer cells (Kim and Choi, 2010). In addition, 5-hydroxy-3,6,7,8,3',4'hexamethoxyflavone isolated from $80 \%$ ethanolic extract of $H$. fusiforme was also found to possess promising anticancer properties against human AGS carcinoma cells and DR4 in cancer cells (Kim et al., 2012). The isolated compound dose-dependently increased $(1-10 \mu \mathrm{g} / \mathrm{mL})$ the death receptor-associated apoptosis mediators including Fas, Fas L, FADD, TRADD. In addition, Son et al. (2018) proclaimed that ethanol extract from $H$. fusiforme had the potential to reduce azoxymethane-induced colonic aberrant crypt foci (ACF) formation in F344 male rats (5 weeks, $150 \mathrm{~g}$ ). $\mathrm{ACF}$ is a term used to describe the pre-neoplastic lesions in the colon which progress into colorectal cancers (Son et al., 2018). Kang et al. (2011) noted that ethyl alcohol extract of $H$. fusiforme had the potential to induce apoptosis in human leukemia U937 cells. Their 
results indicated that the down-regulated expression of IAP family members such as IAP-1, IAP-2, and XIAP, as well as inhibition of Bcl-2 proteins were responsible for the apoptotic cell death of U937 cells (Kang et al., 2011).

Ermakova et al. (2011) attempted to studied the anticancer properties of fucoidans isolated from three seaweed species grown in the Korean costs including $S$. hornery, E. cava, and Costaria costata. According to their results, fucoidans $(100 \mu \mathrm{g} / \mathrm{mL})$ inhibited the colony formation of skin melanoma cell (SK-MEL-28) and the colon cancer cells (DLD-1). Cervical carcinoma is a major cancer in women globally and threatens the health of females who are in the reproductive age (Zhai et al., 2014). Crude polysaccharides from L. Japonica were evaluated against two cervical carcinoma cells (HeLa and U14) to explore the potential of L. Japonica polysaccharides to develop as anticancer drugs (Zhai et al., 2014). According to the results, L. Japonica polysaccharide induced apoptosis in $\mathrm{HeLa}$ and $\mathrm{U} 14$ cells with $\mathrm{IC}_{50}$ values of 85.74 and $76.91 \mu \mathrm{g} /$ $\mathrm{mL}$, respectively. The nasopharyngeal carcinoma cells inhibitory effect of a polysaccharide separated from L. Japonica was recently documented by Zeng et al. (2017). In this study, the authors demonstrated that the administration of $12.5-50 \mathrm{mg} / \mathrm{kg}$ polysaccharide had significant inhibitory effect on tumor growth (nasopharyngeal cancer cell transplanted BALB/C nude mouse). In another recent study, fucoxanthin isolated from L. Japonica was evaluated for its anticancer effect on lung cancer cells including A549, H460, SPC$\mathrm{A} 1$, and H1299. In this study, the up-regulated expression of $\mathrm{p} 53$, p21 $1^{\text {wafl/cipl }}$, PUMA, and FAS and the down-regulated expression of Bcl-2 were found to be responsible for inducing apoptosis in tested cancer cells (Mei et al., 2017). In addition to fucoxanthin, a watersoluble polysaccharide separated from L. Japonica was found to possess anticancer properties in mouse (female kunming mouse) bearing H22 liver cancer cells as well as in vitro in H22 hepatoma cells. Moreover, they found that administration of polysaccharides induced the expression levels of interleukin-2 (IL-2), TNF- $\alpha$ and inhibited the expression of vascular endothelial growth factor (Zhu et al., 2016).

Synytsya et al. (2010) evaluated the anticancer properties of fucoidan isolated from U. pinnatifida using four cancer cell lines, including cervical cancer cells (HeLa), prostate cancer cells (PC3 ), carcinomic human alveolar basal epithelial cells (A549), and hepatocellular carcinoma cells (HepG2). According to the results, fucoidans had considerable anticancer effect against all tested cancer cells at concentrations of $0-0.8 \mathrm{mg} / \mathrm{mL}$. However, the authors reported that fucoidans from $U$. pinnatifida had slightly lower activity than the commercial fucoidan against PC-3 and A549 cancer cells (Synytsya et al., 2010). Other than the aforementioned studies, Cho et al. (1997) studied anti-mutagenic and anticancer properties of 9 seaweeds collected from Korean peninsula including ceylon moss, chlorella, sea lettuce, sea mustard, sea tangle, sporophyll of sea mustard, and purple laver. The authors assessed the anticancer effect of $20 \%$ methanolic extracts collected from the aforementioned seaweeds on Salmonella typhimurium TA100 cells and human colon cancer (HT-29) cells. The $20 \%$ methanol extracts had strong anti-mutagenic activity against aflatoxin $\mathrm{B}_{1}$ and $\mathrm{N}$-methyl -N'-nitro-N-nitrosoguanidine in S. typhimurium TA 100. Moreover, sea mustard extracts, and sea tangle had cytotoxic effects on HT-29 human colon carcinoma cells at the $0.2 \mathrm{mg} / \mathrm{mL}$ (Cho et al., 1997). Table 2. represent some anticancer properties reported in edible Korean seaweeds.

\subsection{Anti-inflammatory activity}

Senevirathna et al. (2012) studied the nitric oxide (NO) inhibi- tory effect of L. japonica enzymatic digests on lipopolysaccharide (LPS)-stimulated RAW 264.7 cells. According to the results, Celluclast- and AMG enzyme-assisted digests had more than $60 \% \mathrm{NO}$ inhibition at concentrations between 50 and $500 \mu \mathrm{g} / \mathrm{mL}$ compared to the LPS-stimulated RAW 264.7 cells (Sevevirathne et al., 2012). Jung et al. (2013) attempted to evaluate the in vitro anti-inflammatory activities of fucosterol and seven phlorotannins (phloroglucinol, eckol, dieckol, phlorofucofuroeckol-A, dioxinodehydroeckol, 7-phloroeckol) collected from edible brown seaweed $E$. bicyclis. The results revealed that the seven phlorotannins isolated from E. bicyclis effectively inhibited the LPS-Induced NO production via down-regulating inducible NO synthase (iNOS) and cyclooxygenase-2 (COX-2) protein expression in LPS-stimulated RAW 264.7 cells. Additionally, fucosterol inhibited tert-butylhydroperoxide-induced ROS production and down-regulated the expression of iNOS and COX-2 protein expressions (Jung et al., 2013). Gwon et al. (2013) investigated the anti-inflammatory effect of the hexane fraction of S. fulvellum in LPS-induced RAW 264.7 cells and phorbol 12-myristate 13-acetate (PMA)-induced mouse-ear edema. The results revealed that $S$. fulvellum extracts had the potential to inhibit the LPS-induced inflammatory responses in macrophages by reducing NF- $\mathrm{BB}$ transcriptional activity and $\mathrm{NF}-\kappa \mathrm{B}$ translocation into the nucleus by inhibiting phosphorylation of inhibitor $\kappa \mathrm{B}-\alpha$. Additionally, down-regulated expression of Akt and mitogen-activated protein kinases (MAPKs) in the LPSstimulated RAW 264.7 cells was also observed in this study. In addition, $S$. fulvellum extracts suppressed PMA-induced mouse-ear edema.

Cho et al. (2007) studied the anti-inflammatory effect of dichloromethane, ethanol, and boiling water extracts of the brown seaweeds $U$. pinnatifida and L. japonica using a BALB/c mouse model. The ethanol and dichloromethane $(0.4 \mathrm{mg} / \mathrm{ear})$ extracts of $U$. pinnatifida inhibited inflammatory symptoms induced by phorbol 12-myristate 13-acetate (PMA) in mouse ear edema by 95.3 and $65.5 \%$, respectively (Cho et al., 2007). Furthermore, Khan et al. (2009) studied the protective effect of $U$. pinnatifida methanol extracts on PMA induced ear edema in BALB/c mouse model. According to the results, the methanol extract of the seaweed had considerable protective effect in ear edema induced by PMA, with an $\mathrm{IC}_{50}$ of $10.3 \mathrm{mg} / \mathrm{mL}$. Nevertheless, compared to the study carried out by Cho et al. (2006) the ethanol extract of $U$. pinnatifida had more than 25 times activity against PMA induced ear edema in $\mathrm{BALB} / \mathrm{c}$ mouse compared to the methanol extract of $U$. pinnatifida. In contrast to the organic solvent extraction methods, supercritical fluid extraction (SFE) method is a novel green extraction technique which has the potential to increase the bioactive compounds recovery, reduce the environmental pollution, and enhance the extraction rates (da Silva et al., 2016). Kang et al. (2016) attempted to evaluate the anti-inflammatory effects of $U$. pinnatifida using SFE in a BALB/c mouse (8-10 weeks old, 20-25 $\mathrm{g}$ body weight) model. In this study, the authors reported that the essential oil from $U$. pinnatifida had a protective effect against $\mathrm{BALB} / \mathrm{c}$ mouse ear inflammation induced by PMA, with $\mathrm{IC}_{50}$ values of 87, 134, and $158 \mu \mathrm{g}$ per ear for edema, erythema, and blood flow, respectively (Kang et al., 2016). Fucoidan isolated from $U$. pinnatifida also possessed anti-inflammatory properties against IL$1 \beta$-induced COX-2 expression in rabbit articular chondrocytes in a dose-dependent $(0-100 \mu \mathrm{g})$ and time-dependent $(0-48 \mathrm{~h})$ manner (Phull et al., 2017).

Microglial cells (BV-2) are specialized macrophage-like immune cells present in the central nervous system, which are involved in the initiation of innate immune responses. Specifically, the activated cells are responsible for the production of pro-inflammatory mediators such as NO, prostaglandin E2 $\left(\mathrm{PGE}_{2}\right)$, and 
TNF- $\alpha$ (Kang et al., 2013). Jung et al. (2007) reported that the methanolic extract obtained from $H$. fusiforme had a suppressive effect on TNF- $\alpha$ production in LPS-stimulated BV-2 cells. According to the results, pre-incubation of $H$. fusiforme extract together with BV-2 cells prior to LPS stimulation inhibited the LPS-induced TNF- $\alpha$ production by inhibiting the nuclear factor$\kappa \mathrm{B}$ (NF-kB) translocation (Jung et al., 2007). Kang et al. (2013) evaluated the anti-inflammatory effects of 5-hydroxy-3,6,7,8,3'4'hexamethoxyflavone isolated from $\mathrm{H}$. fusiforme. In this study the authors demonstrated that the isolated compound had the potential to suppress NF- $\mathrm{B}$ associated proteins in LPS-induced BV-2 cells. Lee and Kang (2015) attempted to evaluate the anti-inflammatory effects of $70 \%$ ethanol extract collected from $H$. fusiformis using BV-2 microglial cells. Accordingly, pretreatment of $H$. fusiformis extract $(0-100 \mu \mathrm{g} / \mathrm{mL})$ inhibited the activation of BV-2 cells through down-regulation of inflammation-related gene expression (iNOS) and inhibiting pro-inflammatory cytokine production including TNF- $\alpha$ and IL-6.

\subsection{Immunomodulation properties}

Other than anti-inflammatory properties, some brown seaweed metabolites were found to possess immunomodulatory properties under in vitro and in vivo conditions. Park et al. (2017) attempted to study the immunomodulatory properties of extract separated from $H$. fusiforme using RAW 264.7 macrophage and using seven weeks old male C57BL mouse model (Park et al., 2017). According to the results, pre-incubation of $H$. fusiforme extract with RAW 264.7 cells increased the production of NO, $\mathrm{PGE}_{2}$, and TNF- $\alpha$ activity in murine macrophage cells at concentrations of 0-200 $\mu \mathrm{g} /$ $\mathrm{mL}$ without altering cell viability. Specifically, the authors found that the active compound in the extract was fucosterol which was responsible for the immunomodulatory properties of Khan the extract. Jeong et al. (2015) attempted to evaluate the immunomodulatory properties of polysaccharides separated from $H$. fusiforme using murine macrophage and splenocytes. According to the results, the polysaccharides exposed cells dose-dependently induced the production of $\mathrm{NO}$, iNOS, and inflammation related cytokine production from macrophage cells (Jeong et al., 2015). In another study, Feng et al. (2015) reported the immunomodulatory effects of a homogeneous polysaccharide (molecular mass of $2.24 \times 10^{6} \mathrm{Da}$ ) separated from L. japonica. The isolated polysaccharide induced the activation of macrophage cells by up-regulating inflammation associated signal pathways such as NF- $\mathrm{kB}$ and MAPK (Fang et al., 2015). In addition, Zha et al. (2015) also reported a polysaccharide isolated from $L$. japonica (molecular mass of $2.89 \times 10^{6}$ Da) has a potential to act as immunostimulaory agent. Specifically, in this study the authors observed that the isolated polysaccharide had the potential to upregulate proteins associated with NF- $\kappa \mathrm{B}$ and MAPKs signaling pathways in RAW 264.7 cells (Zha et al., 2015). Table 3. illustrates some anti-inflammatory and immune-modulatory properties reported from edible Korean brown seaweeds with their references.

\subsection{Antidiabetic and Anti-obesity activities}

Kim and Lee (2012) evaluated the anti-obesity properties of fucoidan isolated from $U$. pinnatifida. The authors evaluated the obesity-specific therapeutic property of fucoidan in 3T3-L1 adipocytes. According to the results, exposure of adipocytes to fucoidan $(1-100 \mu \mathrm{g} / \mathrm{mL})$ inhibited the activation of key markers in adipocyte differentiation including CCAAR/enhancer-binding protein $\alpha, \operatorname{PPAR} \gamma$, and adipocyte protein-2 proteins as well as activation of TNF $\alpha, \mathrm{MCP}-1$, and PAI-1 in 3T3-L1 cells (Kim and Lee, 2012). Kim et al. (2014) reported in vivo anti-obesity effect of fucoidan purchased from a commercial outlet (Haewon Biotech, Seoul, Korea). The authors studied the anti-obesity activity using a high fat diet (HFD)-induced obesity in C57BL/6 mouse model. Their results revealed that, HFD $+1 \%$ fucoidan and HFD $+2 \%$ fucoidan suppressed mRANA expression of aP2, PPAR $\gamma$, and ACC in epididymal fat tissues compared to the only HFD administrated group (Kim et al., 2014). Oh et al. (2016) studied the anti-inflammatory and anti-diabetic effects of four brown seaweeds (U. Pinnatifida, L. Japonica, S. fulvellum, and H. fusiforme) in a high-fat diet-induced obese mouse. The authors reported that mouse fed $L$. Japonica with HFD had improved insulin resistance and reduced circulating pro-inflammatory cytokines despite being obese. In addition, supplementation of HFD with U. Pinnatifida, S. fulvellum, and $H$. fusiforme reduced inflammation in the absence of decreased adipose depot mass and improvement of insulin resistance male C57BL/6N mouse (Oh et al., 2016). Polysaccharide isolated from L. japonica was also found to possess antidiabetic properties in mouse with alloxan-induced diabetes (Jia et al., 2014). According to the authors, administration of $L$. japonica $(200 \mathrm{mg} / \mathrm{kg}$ for 28 days) prevented body-weight loss, fasting blood glucose levels, and increased serum insulin levels in diabetic mouse. In addition, the tested polysaccharide decreased the total cholesterol, triglycerides, and low-density lipoprotein-cholesterol levels, and increased high-density lipoprotein-cholesterol levels in diabetic mouse.

\subsection{Anti-microbial properties}

Thompson and Dragar (2004) attempted to evaluate antiviral properties of a galactofucan isolated from $U$. pinnatifida against herpes simplex virus (HSV). In this study, the authors evaluated, antiviral activity of 32 clinical strains of HSV which included 14 strains of HSV-1 and 18 strains of HSV-2. Enterovirus 71 is a major etiological agent of hand, foot, and mouth disease as well as being is responsible for severe neurological symptoms developed in young children (Yue et al., 2017). Recently, Yue et al. (2017) assessed inhibitory effects of a polysaccharide purified from $L$. japonica against Enterovirus 71 (E71). In this study, the authors reported that the incubation of RD cells with isolated polysaccharides had the potential to reduce infection of E71 to human RD cells in a dose- and time-dependent manner. Cao et al. (2016) reported that polysaccharide separated from $L$. japonica has inhibitory effect on respiratory syncytial virus. The results revealed the polysaccharide extracted from $L$. japonica had a dose-dependent inhibitory effect on respiratory syncytial virus replication (Cao et al., 2016). In addition to antiviral activity, Liu et al. (2017) reported that depolymerized fucoidans separated from L. japonica had the potential to suppress the growth of Staphylococcus aureus and Escherichia coli at concentrations between 5 and $10 \mathrm{mg} / \mathrm{mL}$ (Liu et al., 2017). Additionally, methanolic extract separated from $H$. fusiformis were found to possess antibacterial properties against several pathogenic bacterial strains including Escherichia coli, S. aureus, Bacillus subtilis, Enterobacter aerogenes, and Shewanella sp (Ming-Jiang et al., 2016).

Antimicrobial properties of ethanolic extract separated from $S$. fulvellum were previously assessed by Yoon et al. (2010). The authors reported that, S. fulvellum extract inhibited the growth of several bacterial pathogens including, B. subtilis, Clostridium perfringens, Lactobacillus plantarum, S. aureus, Listeria monocytogenes, Saccharomyces cerevisae, and Candida tropicalis at a concentration of $4 \mathrm{mg} / \mathrm{mL}$ (agar diffusion assay) (Yoon et al., 2010). 
Table 3. Anti-inflammatory and immune-modulatory properties reported from edible Korean brown seaweeds

\begin{tabular}{|c|c|c|c|}
\hline Seaweed & Active compound/fraction & Effect & Reference \\
\hline \multirow[t]{4}{*}{ L. japonica } & Celluclast enzyme assisted extract & $\begin{array}{l}\text { Nitric oxide (NO) inhibitory properties on } \\
\text { LPS-stimulated RAW } 264.7 \text { cells }\end{array}$ & Sevevirathne et al., 2012 \\
\hline & Boiling water extracts & $\begin{array}{l}\text { Inhibitory effect on PMA induced } \\
\text { inflammation in mouse model }\end{array}$ & Cho et al., 2007 \\
\hline & Purified sulphated polysacharide & Induced activation of NF-KB and MAPK signal pathways & Zha et al., 2015 \\
\hline & $\begin{array}{l}\text { Homogeneous polysaccharide } \\
\left(2.24 \times 10^{6} \mathrm{Da}\right)\end{array}$ & Induced activation of NF-KB and MAPK signal pathways & Fang et al., 2015 \\
\hline \multirow[t]{5}{*}{$\begin{array}{l}H . \\
\text { fusiforme }\end{array}$} & Methanolic extract & $\begin{array}{l}\text { Suppressive effect on TNF- } \alpha \text { production } \\
\text { in LPS-stimulated BV- } 2 \text { cells }\end{array}$ & Jung et al., 2007 \\
\hline & $70 \%$ ethanolic extract & $\begin{array}{l}\text { Inhibit TNF- } \alpha \text { and IL- } 6 \text { production } \\
\text { in LPS-induced BV-2 cells }\end{array}$ & Lee and Kang, 2015 \\
\hline & $\begin{array}{l}\text { 5-Hydroxy-3,6,7,8,3'4'- } \\
\text { hexamethoxyflavone }\end{array}$ & $\begin{array}{l}\text { Suppress NF- } \mathrm{KB} \text { associated proteins } \\
\text { in LPS-induced BV-2 cells }\end{array}$ & Kang et al., 2013 \\
\hline & Fucosterol rich extract & $\begin{array}{l}\text { Induced production of NO, } \mathrm{PGE}_{2} \text {, and } \\
\text { TNF- } \alpha \text { from macrophage cells }\end{array}$ & Park et al., 2017 \\
\hline & Crude polysaccharides & $\begin{array}{l}\text { induced the production of NO, iNOS, and inflammation } \\
\text { related cytokine production from macrophage cells }\end{array}$ & Jeong et al., 2015 \\
\hline S. fulvellum & Hexane fraction & $\begin{array}{l}\text { Inhibitory effect on NF-kB associated } \\
\text { signal molecule expression }\end{array}$ & Gwon et al., 2013 \\
\hline \multirow[t]{2}{*}{ E. cava } & Ethanolic extracts & Suppressor of cytokine signalling & Kim et al., 2008 \\
\hline & Phlorotannins & $\begin{array}{l}\text { Inhibits histamine release on human basophilic leukamia } \\
\text { (KU812) and rat basophilic leukamia (RBL-2H3) }\end{array}$ & Le et al., 2009 \\
\hline \multirow[t]{4}{*}{$\begin{array}{l}\text { U. } \\
\text { pinnatifida }\end{array}$} & Boiling water extracts & $\begin{array}{l}\text { Inhibitory effect on PMA induced } \\
\text { inflammation in mouse model }\end{array}$ & Cho et al., 2007 \\
\hline & Methanol extract & $\begin{array}{l}\text { Protective effect against mouse ear } \\
\text { edema induced by PMA }\end{array}$ & Khan et al., 2009 \\
\hline & Supercritical fluid extracts & $\begin{array}{l}\text { PMA induced ear edema, erythema, } \\
\text { and blood flow in mouse model }\end{array}$ & da Silva et al., 2016 \\
\hline & Fucoidan & $\begin{array}{l}\text { IL-1 } 1 \beta \text {-induced COX- } 2 \text { expression in } \\
\text { rabbit articular chondrocytes }\end{array}$ & Phull et al., 2017 \\
\hline
\end{tabular}

\subsection{Anti-coagulant properties}

Heparin is a well-known commercial anticoagulant drug available in the market. However, oral administration of heparin and lowmolecular-weight heparin is limited because the enzymes secreted by bacteria in the gut increase the degradation and desulfation before those anticoagulants enter to the blood circulation (Zhao et al., 2016). Zhao et al. (2016) evaluated the antithrombotic activity of orally administered low-molecular-weight fucoidan isolated from L. Japonica. According to the authors, the low-molecular-weight fucoidan $(7.6 \mathrm{kDa})$ had better absorption and antithrombotic activity in male wistar rats than the medium-molecular-weight fucoidan (35 kDa). Specifically, oral administration of the low-molecularweight fucoidan at $400-800 \mathrm{mg} / \mathrm{kg}$ prolonged the activated partial thromboplastin time (APTT) and thrombin time (TT) in male wistar rats. Anticoagulant properties of a sulfated polysaccharide isolated from E. cava and commercial fucoidan was earlier assessed by Wijesinghe et al. (2011). The results revealed the polysaccharide isolated from $E$. cava had strong anticoagulant activity compared to that of a commercial fucoidan in APTT, TT, and prothrombin time (PT) clotting assays in vitro (Wijesinghe et al.,
2011).

\section{Conclusions}

Edible brown seaweeds are abundant in the coastal areas of the Korean peninsula and its Islands such as Jeju. This review reports on the available edible Korean brown seaweeds, dealing with health promotion properties and compounds being isolated from Korean edible brown seaweeds. Most of the studies reported that, the isolated compounds and crude extracts isolated from these seaweeds exhibited promising bioactive properties such as antioxidant, anticancer, anti-inflammatory, immunomodulatory, anti-diabetic, antimicrobial, and anti-coagulant effects. Some comparative studies reported the secondary metabolites present in these edible seaweeds which are more active than the commercial drugs. However, most of the studies limited to cultured cells and/or with laboratory animals like zebrafish or mouse models. Lack of clinical trials and detail investigations with those extracts reduced the industrial level applications of this untapped resource. Therefore, continued research with those identified compounds is required to develop 
functional products such as cosmeceuticals, nutraceuticals, functional foods, and commercial drugs. In addition, dissemination of scientific results to general population is an important requirement to increase seaweed consumption all around the world. Future research work dealing with edible Korean seaweed bioactivities should be focus to explain the mode of action of isolated compounds under in vivo conditions. These approaches will be a useful approach to develop industrially useful products.

\section{Reference}

Cao, Y.G., Hao, Y., Li, Z.H., Liu, S.T., and Wang, L.X. (2016). Antiviral activity of polysaccharide extract from Laminaria japonica against respiratory syncytial virus. Biomed. Pharmacother. 84(Supplement C): $1705-1710$

Cha, S.H., Ko, C.I., Kim, D., and Jeon, Y.J. (2012). Protective effects of phlorotannins against ultraviolet B radiation in zebrafish (Danio rerio) Vet. Dermatol. 23(1): 51-56, e12.

Cho, E.J., Rhee, S.H., and Park, K.Y. (1997). Antimutagenic and cancer cell growth inhibitory effects of seaweeds. Prev. Nutr. Food Sc. 2(4): 348-353.

Cho, J.Y., Kang, J.Y., Khan, M.N.A., Park, N.H., Kim, S.K., and Hong, Y.K. (2007). Anti-inflammatory activities of Undaria pinnatifida and Laminaria japonica (Phaeophyta). Fish. Aquat. Sci. 10(3): 127-132.

Choi, D.S., Athukorala, Y., Jeon, Y.J., Senevirathne, M., Cho, K.R., and Kim, S.H. (2007a). Antioxidant activity of sulfated polysaccharides isolated from Sargassum fulvellum. Prev. Nutr. Food Sc. 12(2): 65-73.

Choi, E.Y., Hwang, H.J., Kim, I.H., and Nam, T.J. (2009). Protective effects of a polysaccharide from Hizikia fusiformis against ethanol toxicity in rats. Food Chem. Toxicol. 47(1): 134-139.

Choi, H.G., Kim, Y.S., Kim, J.H., Lee, S.J., Park, E.J., Ryu, J., and Nam, K.W. (2007b). Effects of temperature and salinity on the growth of Gracilaria verrucosa and $G$. chorda, with the potential for mariculture in Korea. In: Anderson, RBrodie, JOnsøyen, E, and Critchley, AT (Ed.). Eighteenth International Seaweed Symposium: Proceedings of the Eighteenth International Seaweed Symposium, held in Bergen, Norway, 20-25 June 2004 . Springer Netherlands, Dordrecht: 43-51.

Choi, Y.S., Choi, J.H., Han, D.J., Kim, H.Y., Kim, H.W., Lee, M.A., Chung, H.J., and Kim, C.J. (2012). Effects of Laminaria japonica on the physicochemical and sensory characteristics of reduced-fat pork patties. Meat Sci. 91(1): 1-7.

Cui, C., Lu, J., Sun-Waterhouse, D., Mu, L., Sun, W., Zhao, M., and Zhao, H. (2016). Polysaccharides from Laminaria japonica: structural characteristics and antioxidant activity. LWT - Food Sci. Technol. 73(Supplement C): 602-608.

da Silva, R.P.F.F., Rocha-Santos, T.A.P., and Duarte, A.C. (2016). Supercritical fluid extraction of bioactive compounds. TrAC, Trends Anal. Chem. 76: 40-51.

De Zoysa, M., Nikapitiya, C., Jeon, Y.J., Jee, Y., and Lee, J. (2008). Anticoagulant activity of sulfated polysaccharide isolated from fermented brown seaweed Sargassum fulvellum. J. Appl. Phycol. 20(1): 67-74.

Dembitsky, V.M., and Maoka, T. (2007). Allenic and cumulenic lipids. Prog. Lipid Res. 46(6): 328-375.

Ermakova, S., Sokolova, R., Kim, S.M., Um, B.H., Isakov, V., and Zvyagintseva, T. (2011). Fucoidans from brown seaweeds Sargassum hornery, Eclonia cava, Costaria costata: structural characteristics and anticancer activity. Appl. Biochem. Biotechnol. 164(6): 841-850.

Fang, Q., Wang, J.F., Zha, X.Q., Cui, S.H., Cao, L., and Luo, J.P. (2015). Immunomodulatory activity on macrophage of a purified polysaccharide extracted from Laminaria japonica. Carbohydr. Polym. 134(Supplement C): 66-73.

Fletcher, H.R., Biller, P., Ross, A.B., and Adams, J.M.M. (2017). The seasonal variation of fucoidan within three species of brown macroalgae. Algal Res. 22: 79-86.

Gupta, S., and Abu-Ghannam, N. (2011). Bioactive potential and possible health effects of edible brown seaweeds. Trends Food Sci. Technol. 22(6): 315-326

Gwon, W.G., Lee, M.S., Kim, J.S., Kim, J.I., Lim, C.W., Kim, N.G., and Kim,
H.R. (2013). Hexane fraction from Sargassum fulvellum inhibits lipopolysaccharide-induced inducible nitric oxide synthase expression in RAW 264.7 cells via NF-kappaB pathways. Am. J. Chin. Med. 41(3): $565-584$.

Handique, J.G., and Baruah, J.B. (2002). Polyphenolic compounds: an overview. React. Funct. Polyme. 52(3): 163-188.

Harborne, J.B. (1998). Phytochemical methods a guide to modern techniques of plant analysis. Springer Science \& Business Media.

Hu, Z.M., Zhang, J., Lopez-Bautista, J., and Duan, D.L. (2013). Asymmetric genetic exchange in the brown seaweed Sargassum fusiforme (Phaeophyceae) driven by oceanic currents. Mar. biol. 160(6): 1407-1414.

Hwang, E.K., Baek, J.M., and Park, C.S. (2007). Assessment of optimal depth and photon irradiance for cultivation of the brown alga, Sar gassum fulvellum (Turner) C. Agardh. J. Appl. Phycol. 19(6): 787-793.

Hwang, E.K., Gong, Y.G., Hwang, I.K., Park, E.J., and Park, C.S. (2012a). Cultivation of the two perennial brown algae Ecklonia cava and $E$. stolonifera for abalone feeds in Korea. J. Appl. Phycol. 25(3): 825829.

Hwang, S.H., Jang, J.M., and Lim, S.S. (2012b). Isolation of fucosterol from Pelvetia siliquosa by high-speed countercurrent chromatography. Fish. Aquat. sci. 15(3): 191-195.

Islam, M.N., Ishita, I.J., Jin, S.E., Choi, R.J., Lee, C.M., Kim, Y.S., Jung, H.A., and Choi, J.S. (2013). Anti-inflammatory activity of edible brown alga Saccharina japonica and its constituents pheophorbide a and pheophytin a in LPS-stimulated RAW 264.7 macrophage cells. Food. Chem Toxicol. 55: 541-548.

Jeong, S.C., Jeong, Y.T., Lee, S.M., and Kim, J.H. (2015). Immune-modulating activities of polysaccharides extracted from brown algae Hizikia fusiforme. Biosci. Biotechnol. Biochem. 79(8): 1362-1365.

Jia, X., Yang, J., Wang, Z., Liu, R., and Xie, R. (2014). Polysaccharides from Laminaria japonica show hypoglycemic and hypolipidemic activities in mice with experimentally induced diabetes. Exp. Biol. Med (Maywood). 239(12): 1663-1670.

Jung, H.A., Jin, S.E., Ahn, B.R., Lee, C.M., and Choi, J.S. (2013). Anti-inflammatory activity of edible brown alga Eisenia bicyclis and its constituents fucosterol and phlorotannins in LPS-stimulated RAW264.7 macrophages. Food Chem. Toxicol. 59: 199-206.

Jung, K., Ha, E., Uhm, Y., Park, H., Kim, M.J., Kim, H., Baik, H., Hong, M., Yang, J., and Yim, S.V. (2007). Suppressive effect by Hizikia fusiforme on the production of tumor necrosis factor in BV2 murine microglial cells. Neurol Res. 29(Suppl 1): S88-92.

Kang, C.H., Kang, S.H., Boo, S.H., Park, S.Y., Moon, D.O., and Kim, G.Y. (2011). Ethyl alcohol extract of Hizikia fusiforme induces caspasedependent apoptosis in human leukemia U937 cells by generation of reactive oxygen species. Trop. J. Pharm. Res. 10(6): 739-746.

Kang, C.H., Kim, M.J., Seo, M.J., Choi, Y.H., Jo, W.S., Lee, K.T., Jeong, Y.K., and Kim, G.Y. (2013). 5-Hydroxy-3,6,7,8,3'4'-hexamethoxyflavone inhibits nitric oxide production in lipopolysaccharide-stimulated BV2 microglia via NF-kappaB suppression and Nrf-2-dependent heme oxygenase-1 induction. Food Chem. Toxicol. 57(Supplement C): $119-125$

Kang, J.Y., Chun, B.S., Lee, M.C., Choi, J.S., Choi, I.S., and Hong, Y.K. (2016) Anti-inflammatory Activity and Chemical Composition of Essential Oil Extracted with Supercritical $\mathrm{CO} 2$ from the Brown Seaweed Undaria pinnatifida. J. Essent. Oil Bear. PI. 19(1): 46-51.

Kang, J.Y., Khan, M.N., Park, N.H., Cho, J.Y., Lee, M.C., Fujii, H., and Hong, Y.K. (2008). Antipyretic, analgesic, and anti-inflammatory activities of the seaweed Sargassum fulvellum and Sargassum thunbergii in mice. J. Ethnopharmacol. 116(1): 187-190.

Khan, M.N.A., Yoon, S.J., Choi, J.S., Park, N.G., Lee, H.H., Cho, J.Y., and Hong, Y.K. (2009). Anti-Edema Effects of Brown Seaweed (Undaria pinnatifida) Extract on Phorbol 12-Myristate 13-Acetate-Induced Mouse Ear Inflammation. Am. J. Chin. Med. 37(02): 373-381.

Kim, A., Bing, S.J., Cho, J., Ahn, G., Lee, J.-H., Jeon, Y.-J., Lee, B.-G., and Jee, Y. (2015). Protective effect of Hizikia fusiforme on radiation-induced damage in splenocytes. Korean J. Vet. Res. 55(1): 21-30.

Kim, K.J., and Lee, B.Y. (2012). Fucoidan from the sporophyll of Undaria pinnatifida suppresses adipocyte differentiation by inhibition of inflammation-related cytokines in 3T3-L1 cells. Nutr. Res. 32(6): 439-447.

Kim, M.J., Jeon, J., and Lee, J.S. (2014). Fucoidan Prevents High-Fat Diet- 
Induced Obesity in Animals by Suppression of Fat Accumulation. Phytother. Res. 28(1): 137-143.

Kim, M.J., Lee, H.H., Seo, M.J., Kang, B.W., Park, J.U., Kim, K.-S., Kim, G.Y., Joo, W.H., Choi, Y.H., and Cho, Y.-S. (2012). Identification of 5-hydroxy-3, 6, 7, 8, 3', 4'-hexamethoxyflavone from Hizikia fusiforme involved in the induction of the apoptosis mediators in human AGS carcinoma cells. J. Microbiol. Biotechnol. 22(12): 1665-1672.

Kim, S.K., Lee, D.Y., Jung, W.K., Kim, J.H., Choi, I., Park, S.G., Seo, S.K., Lee, S.W., Lee, C.M., Yea, S.S., Choi, Y.H., and Choi, I.W. (2008). Effects of Ecklonia cava ethanolic extracts on airway hyperresponsiveness and inflammation in a murine asthma model: Role of suppressor of cytokine signaling. Biomed. Pharmacother. 62(5): 289-296.

Kim, S.K., and Ta, Q.V. (2011). Potential beneficial effects of marine algal sterols on human health. Adv. Food Nutr. Res. 64: 191-198.

Kim, S.O., and Choi, Y.H. (2010). The ethyl alcohol extract of Hizikia fusiforme inhibits matrix metalloproteinase activity and regulates tight junction related protein expression in Hep3B human hepatocarcinoma cells. J. Med. Food. 13(1): 31-38.

Kim, T.Y., Jin, C.Y., Kim, G.Y., Choi, I.W., Jeong, Y.K., Nam, T.J., Kim, S.K., and Choi, Y.H. (2009). Ethyl alcohol extracts of Hizikia fusiforme sensitize AGS human gastric adenocarcinoma cells to tumor necrosis factorrelated apoptosis-inducing ligand-mediated apoptosis. J. Med. Food. 12(4): 782-787.

Kim, Y.K. (2010). Total phenolic contents and antioxidant activities of Undaria pinnatifida and Capsosiphon fulvescens. Korean J. Food Cook Sci. 26(5): 499-502.

Le, Q.T., Li, Y., Qian, Z.J., Kim, M.M., and Kim, S.K. (2009). Inhibitory effects of polyphenols isolated from marine alga Ecklonia cava on histamine release. Process Biochem. 44(2): 168-176.

Lee, P.P., Lin, Y.H., Chen, M.C., and Cheng, W. (2017). Dietary administration of sodium alginate ameliorated stress and promoted immune resistance of grouper Epinephelus coioides under cold stress. Fish Shellfish Immunol. 65: 127-135.

Lee, S.G., and Kang, H. (2015). Evaluation of antioxidant and anti-neuroinflammatory activities of Hizikia fusiformis (Harvey) Okamura extract. Trop. J. Pharm. Res. 14(3): 463-468.

Lee, S., Lee, Y.S., Jung, S.H., Kang, S.S., and Shin, K.H. (2003). Anti-oxidant activities of fucosterol from the marine algae Pelvetia siliquosa. Arch. Pharm. Res. 26(9): 719-722

Lee, Y.S., Shin, K.H., Kim, B.K., and Lee, S. (2004). Anti-diabetic activities of fucosterol from Pelvetia siliquosa. Arch. Pharm. Res. 27(11): 11201122

Li, Y.X., Wijesekara, I., Li, Y., and Kim, S.K. (2011). Phlorotannins as bioactive agents from brown algae. Process Biochem. 46(12): 2219-2224.

Liu, M., Liu, Y., Cao, M.J., Liu, G.M., Chen, Q., Sun, L., and Chen, H. (2017). Antibacterial activity and mechanisms of depolymerized fucoidans isolated from Laminaria japonica. Carbohydr. Polym. 172(Supplement C): 294-305

Manach, C., Williamson, G., Morand, C., Scalbert, A., and Remesy, C. (2005). Bioavailability and bioefficacy of polyphenols in humans. I. Review of 97 bioavailability studies. Am. J. Clin. Nutr. 81(1 Suppl): 230S-242S

Marriott, A.S., Hunt, A.J., Bergstrom, E., Thomas-Oates, J., and Clark, J.H. (2016). Effect of rate of pyrolysis on the textural properties of naturally-templated porous carbons from alginic acid. J. Anal. Appl. Pyrolysis. 121: 62-66.

Matsuno, T. (2001). Aquatic animal carotenoids. Fisheries Science. 67(5): 771-783.

Mei, C., Zhou, S., Zhu, L., Ming, J., Zeng, F., and Xu, R. (2017). Antitumor effects of laminaria extract fucoxanthin on lung cancer. Mar. Drugs. 15(2): 39.

Miyashita, K., and Hosokawa, M. (2018). Health impact of marine carotenoids. J Food Bioact. 1: 31-40.

Ming-Jiang, W., Yue, W., Chang-Qing, T., Qiao, J., and Wei, L. (2016). Antibacterial total phenolic compounds from a brown alga Hizikia Fusiformis. DEStech Transactions on Environment, Energy and Earth Science(sses/icfse). 2016: 418-428.

Mohibbullah, M., Hannan, M.A., Choi, J.Y., Bhuiyan, M.M., Hong, Y.K., Choi, J.S., Choi, I.S., and Moon, I.S. (2015). The edible marine alga Gracilariopsis chorda alleviates hypoxia/reoxygenation-induced oxidative stress in cultured hippocampal neurons. J. Med. Food. 18(9):
960-971.

Mouritsen, O.G., Bagatolli, L.A., Duelund, L., Garvik, O., Ipsen, J.H., and Simonsen, A.C. (2017). Effects of seaweed sterols fucosterol and desmosterol on lipid membranes. Chem. Phys. Lipids. 205: 1-10.

Nakamura, Y., Narukawa, T., and Yoshinaga, J. (2008). Cancer risk to Japanese population from the consumption of inorganic arsenic in cooked hijiki. J. Agric. Food Chem. 56(7): 2536-2540.

Oh, J.H., Kim, J., and Lee, Y. (2016). Anti-inflammatory and anti-diabetic effects of brown seaweeds in high-fat diet-induced obese mice. Nutr. Res. Pract. 10(1): 42-48.

Park, S.K., Kang, J.Y., Kim, J.M., Park, S.H., Kwon, B.S., Kim, G.H., and Heo, H.J. (2018). Protective effect of fucoidan extract from Ecklonia cava on hydrogen peroxide-induced neurotoxicity. J. Microbiol. Biotechnol. 28(1): 40-49.

Park, S.Y., Hwang, E., Shin, Y.K., Lee, D.G., Yang, J.E., Park, J.H., and Yi, T.H. (2017). Immunostimulatory effect of enzyme-modified Hizikia fusiforme in a mouse model in vitro and ex vivo. Mar. Biotechnol (NY). 19(1): 65-75.

Park, S.Y., Kang, S., and Ha, S.D. (2016). Inactivation of murine norovirus-1 in the edible seaweeds Capsosiphon fulvescens and Hizikia fusiforme using gamma radiation. Food Microbiol. 56: 80-86.

Peng, J., Yuan, J.P., Wu, C.F., and Wang, J.H. (2011). Fucoxanthin, a marine carotenoid present in brown seaweeds and diatoms: metabolism and bioactivities relevant to human health. Mar. Drugs. 9(10): 1806-1828

Phull, A.R., Majid, M., Haq, I.U., Khan, M.R., and Kim, S.J. (2017). In vitro and in vivo evaluation of anti-arthritic, antioxidant efficacy of fucoidan from Undaria pinnatifida (Harvey) Suringar. Int. J. Biol. Macromol. 97: 468-480.

Prabhasankar, P., Ganesan, P., Bhaskar, N., Hirose, A., Stephen, N., Gowda, L.R., Hosokawa, M., and Miyashita, K. (2009). Edible Japanese seaweed, wakame (Undaria pinnatifida) as an ingredient in pasta: Chemical, functional and structural evaluation. Food Chem. 115(2): 501-508.

Rioux, L.E., Turgeon, S.L., and Beaulieu, M. (2007). Characterization of polysaccharides extracted from brown seaweeds. Carbohydra. Polym. 69(3): 530-537

Sanjeewa, K.K.A., Fernando, I.P.S., Samarakoon, K.W., Lakmal, H.H.C., Kim, E.A., Kwon, O.N., Dilshara, M.G., Lee, J.B., and Jeon, Y.J. (2016). Anti-inflammatory and anti-cancer activities of sterol rich fraction of cultured marine microalga Nannochloropsis oculata. Algae. 31(3): 277-287.

Sanjeewa, K.K.A., Lee, J.S., Kim, W.S., and Jeon, Y.J. (2017). The potential of brown-algae polysaccharides for the development of anticancer agents: An update on anticancer effects reported for fucoidan and laminaran. Carbohydr. Polym. 177: 451-459.

Sevevirathne, M., Lee, K.H., Ahn, C.B., Park, P.J., and Je, J.Y. (2012). Evaluation of antioxidant, anti-alzheimer's and anti-inflammatory activities of enzymatic hydrolysates from edible brown seaweed (Laminaria japonica). J. Food Biochem. 36(2): 207-216.

Siriwardhana, N., Lee, K.W., Jeon, Y.J., Kim, S.H., and Haw, J.W. (2003). Antioxidant activity of Hizikia fusiformis on reactive oxygen species scavenging and lipid peroxidation inhibition. Revista de Agaroquimica $y$ Tecnologia de Alimentos. 9(5): 339-346.

Son, Y.S., Ullah, H.M.A., Elfadl, A.K., Ghim, S.G., Chung, M.J., Kim, Y.D., Lee, E.J., Kang, K.K., and Jeong, K.S. (2018). Inhibition of formation of azoxymethane-induced colonic aberrant crypt foci in rats by edible green algae Capsosiphon fulvescens and brown algae Hizikia fusiforme. In Vivo. 32(1): 101-108

Stahl, W., and Sies, H. (2003). Antioxidant activity of carotenoids. Mol. Aspects Med. 24(6): 345-351.

Suetsuna, K., and Nakano, T. (2000). Identification of an antihypertensive peptide from peptic digest of wakame (Undaria pinnatifida). J. Nutr. Biochem. 11(9): 450-454.

Synytsya, A., Kim, W.J., Kim, S.M., Pohl, R., Synytsya, A., Kvasnicka, F., Copikova, J., and II Park, Y. (2010). Structure and antitumour activ ity of fucoidan isolated from sporophyll of Korean brown seaweed Undaria pinnatifida. Carbohydr. Polym. 81(1): 41-48.

Targett, N.M., and Arnold, T.M. (1998). Minireview-predicting the effects of brown algal phlorotannins on marine herbivores in tropical and temperate oceans. Journal of Phycology. 34(2): 195-205. 
Tong, T., Li, J., Ko, D.O., Kim, B.S., Zhang, C., Ham, K.S., and Kang, S.G. (2014). In vitro antioxidant potential and inhibitory effect of seaweed on enzymes relevant for hyperglycemia. Food Sci. Biotechnol. 23(6): 2037-2044.

Wang, Z., Liu, T., Chen, X., You, H., Zhang, Q., Xue, J., Zheng, Y., and Luo, D. (2018). Low molecular weight fucoidan ameliorates hindlimb ischemic injury in type 2 diabetic rats. J Ethnopharmacol. 210(Supplement C): 434-442.

Wijesinghe, W.A., and Jeon, Y.J. (2012a). Enzyme-assistant extraction (EAE) of bioactive components: a useful approach for recovery of industrially important metabolites from seaweeds: a review. Fitoterapia. 83(1): 6-12.

Wijesinghe, W.A., and Jeon, Y.J. (2012b). Exploiting biological activities of brown seaweed Ecklonia cava for potential industrial applications: a review. Int. J. Food Sci. Nutr. 63(2): 225-235.

Wijesinghe, W.A.J.P., Athukorala, Y., and Jeon, Y.J. (2011). Effect of anticoagulative sulfated polysaccharide purified from enzyme-assistant extract of a brown seaweed Ecklonia cava on Wistar rats. Carbohydr. Polym. 86(2): 917-921.

Wu, M., Tong, C., Wu, Y., Liu, S., and Li, W. (2016). A novel thyroglobulinbinding lectin from the brown alga Hizikia fusiformis and its antioxidant activities. Food Chem. 201(Supplement C): 7-13.

Wu, M., Wu, Y., Qu, M., Li, W., and Yan, X. (2013). Evaluation of antioxidant activities of water-soluble polysaccharides from brown alga Hizikia fusiformis. Int. J. Biol. Macromol. 56(Supplement C): 28-33.

Yao, Y., Xiang, H., You, L., Cui, C., Sun-Waterhouse, D., and Zhao, M. (2017). Hypolipidaemic and antioxidant capacities of polysaccharides obtained from Laminaria japonica by different extraction media in dietinduced mouse model. Int. J. Food Sci. Technol. 52(10): 2274-2281.

Yin, G., Li, W., Lin, Q., Lin, X., Lin, J., Zhu, Q., Jiang, H., and Huang, Z. (2014). Dietary administration of laminarin improves the growth performance and immune responses in Epinephelus coioides. Fish Shellfish Immunol. 41(2): 402-406.
Yoon, S.Y., Lee, S.Y., Kim, K.B.-W.R., Song, E.J., Lee, S.J., Lee, C.J., Park, N.B., Jung, J.Y., Kwak, J.H., and Nam, K.W. (2010). Antimicrobial activity of the Sargassum fulvellum ethanol extract and the effect of temperature and $\mathrm{pH}$ on their activity. Korean J. Food Sci. Technol. 42(2) 155-159.

Yue, Y., Li, Z., Li, P., Song, N., Li, B., Lin, W., and Liu, S. (2017). Antiviral activity of a polysaccharide from Laminaria japonica against enterovirus 71. Biomed. Pharmacother. 96(Supplement C): 256-262.

Zeng, M., Wu, X., Li, F., She, W., Zhou, L., Pi, B., Xu, Z., and Huang, X. (2017). Laminaria Japonica polysaccharides effectively inhibited the growth of nasopharyngeal carcinoma cells in vivo and in vitro study. Exp. Toxicol. Pathol. 69(7): 527-532.

Zha, S., Zhao, Q., Zhao, B., Ouyang, J., Mo, J., Chen, J., Cao, L., and Zhang, H. (2016). Molecular weight controllable degradation of Laminaria japonica polysaccharides and its antioxidant properties. J. Ocean U. China. 15(4): 637-642.

Zha, X.Q., Lu, C.Q., Cui, S.H., Pan, L.H., Zhang, H.L., Wang, J.H., and Luo, J.P. (2015). Structural identification and immunostimulating activity of a Laminaria japonica polysaccharide. Int. J. Biol. Macromol. 78: 429-438.

Zhai, Q., Li, X., Yang, Y., Yu, L., and Yao, Y. (2014). Antitumor activity of a polysaccharide fraction from Laminaria japonica on U14 cervical carcinoma-bearing mice. Tumour Biol. 35(1): 117-122.

Zhao, D., Xu, J., and Xu, X. (2018). Bioactivity of fucoidan extracted from Laminaria japonica using a novel procedure with high yield. Food Chem. 245: 911-918.

Zhao, X., Guo, F., Hu, J., Zhang, L., Xue, C., Zhang, Z., and Li, B. (2016). Antithrombotic activity of oral administered low molecular weight fucoidan from Laminaria Japonica. Thromb. Res. 144(Supplement C): 46-52.

Zhu, Q., Chen, J., Li, Q., Wang, T., and Li, H. (2016). Antitumor activity of polysaccharide from Laminaria japonica on mice bearing $\mathrm{H} 22$ liver cancer. Int. J. Biol. Macromolecul. 92(Supplement C): 156-158. 